\title{
Board 101: Project Based Learning for a Mechanical Engineering Major Stu- dent: The Sustainability of Internal Combustion Engines (Student Poster)
}

\section{Mr. Aaron Price Barnett}

Aaron Barnett is currently a sophomore at Salt Lake Community College studying Material Science Engineering with a minor in Chemistry. His academic focus includes renewable energy and sustainable materials. As well as helping shape a new generation of engineers and scientists to continue improving the world.

\section{Dr. Nick M. Safai, Salt Lake Community College}

Dr. Nick M. Safai is an ASEE Fellow. He has been an ASEE officer and member for the past 30 years. He has been the six-time elected as the Program Chair of the ASEE International Division for approximately the past 15 years. Three times as the Program Chair for the Graduate Studies Division of ASEE. Nick has had a major role in development and expansion of the ID division. Under his term as the International Division Program Chair the international division expanded, broadened in topics, and the number of sessions increased from a few technical sessions to over eighteen sessions in the recent years. The ASEE International Division by votes, has recognized Nick's years of service through several awards over the past years. Nick has been the recipient of multiple Service awards (examples: 2013, 2010, 2006, 2004, 1996), Global Engineering Educators award (example: 2007, 2005), Best Paper award (examples: 2016, 2010, 2005, 2004, 1995) and other awards from the International Division for exceptional contribution to the international division of the American Society for Engineering Education. Examples of some Awards from other Professional Organizations: - American Society of Civil Engineers (ASCE): Engineering Educator of the Year Award 2004. • Utah Engineers Council, UEC: Engineering Educator of the Year 2005 award, in recognition of outstanding achievements in the field of engineering and for service to society. • SLC Foundation; Salt lake City, Utah: Teaching Excellence Award 2004 and 2012. * SLCC Faculkty Exemplary Service Award April 2015 and 2016. • American Society of Civil Engineers (ASCE): Chapter faculty Advisor recognition award 2002. • Computational Sciences and Education; recognition for outstanding contributions and for exemplary work in helping the division achieve its goals1998. • Engineering Division; recognition for outstanding contributions and for exemplary work in helping the division achieves its goals 1995. • Science and Humanities; recognition for outstanding contributions and for exemplary work in helping the fields achieve its May 1994. • Math \& Physical Sciences; appreciation for academic expertise February 1994.

Academics: Nick Safai received his PhD degree in engineering from the Princeton University, Princeton, New Jersey in 1979. He also did a one year post-doctoral at Princeton University after receiving his degrees from Princeton University. His areas of interest, research topics, and some of the research studies have been; $\bullet$ Multi-Phase Flow through Porous Media $\bullet$ Wave propagation in Filamentary Composite Materials $\bullet$ Vertical and Horizontal Land Deformation in a De-saturating Porous Medium $\bullet$ Stress Concentration in Filamentary Composites with Broken Fibers $\bullet$ Aviation; Developments of New Crashworthiness Evaluation Strategy for Advanced General Aviation • Pattern Recognition of Biological Photomicrographs Using Coherent Optical Techniques Nick also received his four masters; in Aerospace Engineering, Civil Engineering, Operation Research, and Mechanical Engineering all from Princeton University during the years from 1973 through 1976. He received his bachelor's degree in Mechanical engineering, with minor in Mathematics from Michigan State. Nick has served and held positions in Administration (Civil, Chemical, Computer Engineering, Electrical, Environmental, Mechanical, Manufacturing, Bioengineering, Material Science), and as Faculty in the engineering department for the past twenty seven years.

Industry experience: Consulting; since 1987; Had major or partial role in: I) performing research for industry, DOE and NSF, and II) in several oil industry or government (DOE, DOD, and NSF) proposals. Performed various consulting tasks from USA for several oil companies (Jawaby Oil Service Co., WAHA Oil and Oasis Co., London, England). The responsibilities included production planning, forecasting and reservoir maintenance. This production planning and forecasting consisted of history matching and 
prediction based on selected drilling. The reservoir maintenance included: water/gas injection and gas lift for selected wells to optimize reservoir production plateau and prolonging well's economic life.

Terra Tek, Inc., Salt Lake City, UT, 1985-1987; Director of Reservoir Engineering; Responsible of conducting research for reservoir engineering projects, multiphase flow, well testing, in situ stress measurements, SCA, hydraulic fracturing and other assigned research programs. In addition, as a group director have been responsible for all management and administrative duties, budgeting, and marketing of the services, codes and products.

Standard oil Co. (Sohio Petroleum Company), San Francisco, California, 1983-85; Senior Reservoir Engineer; Performed various tasks related to Lisburne reservoir project; reservoir simulation (3 phase flow), budgeting, proposal review and recommendation, fund authorizations (AFE) and supporting documents, computer usage forecasting, equipment purchase/lease justification (PC, IBM-XT, Printer, etc.), selection/justification and award of contract to service companies, lease evaluation, economics, reservoir description and modeling, lift curves, pressure maintenance (gas injection analysis, micellar-flooding, and water-flooding), Special Core Analysis (SCA), PVT correlations, petrophysics and water saturation mapping.

Performed reservoir description and modeling, material balance analysis. Recovery factors for the reservoir. Administrative; coordination and organization of 2 and 6 week workplans, 1982 and 1983 annual specific objectives, monthly reports, recommendation of courses and training program for the group. Chevron Oil Company, 1979- 1983; Chevron Overseas Petroleum Inc. (COPI), San Francisco, California 1981-1983. Project Leader/Reservoir Engineer, Conducted reservoir and some production engineering work using the in-house multiphase model/simulators. Evaluation/development, budgeting and planning for international fields; Rio Zulia field - Columbia, Pennington Field - Offshore Nigeria, Valenginan, Grauliegend and Rothliegend Reservoir - Netherlands. Also represented COPI as appropriate when necessary.

Chevron Geo-Sciences Company, Houston, TX, 1979-1980 Reservoir Engineer Applications, Performed reservoir simulation studies, history matching and performance forecasting, water-flooding for additional recovery (Rangeley Field - Colorado, Windalia Field - Australia), steam-flooding performances (Kern River, Bakersfield, California), gas blowdown and injection (Eugene Island Offshore Louisiana) on domestic and foreign fields where Chevron had an interest, using Chevron's CRS3D, SIS and Steam Tube simulator programs.

Chevron Oil Field Research Co. (COFRC), La Habra 1978-1979, California. Research Engineer, Worked with Three-Phase, Three-Dimensional Black Oil Reservoir Simulator, Steam Injection Simulator, Pipeflow \#2. Also performed history matching and 20-year production forecast including gas lift and desalination plants for Hanifa Reservoir, Abu Hadriya Field (ARAMCO). 


\title{
Project Based Learning for a Mechanical Engineering Major Student: The Sustainability of Internal Combustion Engines
}

\author{
Aaron Barnett (student: Mechanical Engineering Major) \\ Dr. Nick Safai (Professor) \\ Engineering Department, Salt Lake Community College, Salt Lake City, UT 84123 USA
}

The most intimidating choice that students face at the beginning of their university years is the major that they will pursue. At the age of the majority of students, entering universities the students are maturing and learning about themselves, and the world. In today's economy not only are there many more choices offered to them, students for the majority do not have practical knowledge of what future careers may offer or what to expect from them. According to a report by the U.S. Department of Education, among all STEM fields 35\% of students changed their major within the first three years, and within the Engineering and Engineering Technology fields $32 \%$ of students changed their majors within the first three years [1]. Increasingly universities offer various programs to help students understand different majors and possible career options. The author attends a university offers a co-op program in which the student may work in conjunction with a company to gain valuable work related experience and knowledge, or may work on independent research on a topic within the students' field of study with the aid of a professor. I, as the student chose to work on independent research to further my studies within the automotive and engineering industries.

For the co-op program, I chose to study the relationship that the fields of mechanical and material science engineering have with the renewable energy segment of the automotive industry. The research included the review of many case studies from both industry and government agencies, which I will highlight in this paper. The case studies focused on engineering solutions that introduced new or revised methods to further the fuel efficiency of internal combustion engines, while introducing new technologies that aid the development of alternative energy vehicles.

\section{Fuel Saving Technologies}

Technology in the automotive market is improving vehicles to become safer, more efficient, more comfortable, and smarter with features like driver assistance. A few notable technologies are increasing in popularity that assist fuel economy and improved constantly as they mature. One of those technologies is the 'Start-Stop System'; a start-stop system automatically shuts off the engine when the vehicle has come to a rest to cut fuel use and idle emissions. It then restarts the engine automatically when the driver lifts their foot off the brake. "Potential fuel savings are said to be in terms of a range of 3-10 percent, with some venturing as 
high as 12 percent [2].” To test if these claims were accurate, an automotive journalism company, Edmunds, created a test trail with three cars. The three cars they used were; a 2014 Mini Cooper with a 1.5 L turbocharged 2-cylinder engine, a 2014 BMW 328i GT with a $2.0 \mathrm{~L}$ turbocharged 4 cylinders, and a 2015 Jaguar F-Type R with a 5.0 L supercharged V8. The course they used was 80.4 miles of suburban roads in Orange County, California, which consisted of start and stop conditions that took three hours to complete. Each car ran the test twice, except the Mini Cooper, on back-to-back days at the same time of day. The air conditioning was off while testing the BMW and the Jaguar, while there were two tests with the air conditioning on set at 74 degrees Fahrenheit and two tests with the air conditioning off in the Mini Cooper. The results for the BMW, with the system off, used 3.1 gallons, and with the system on it used 2.8 gallons, resulting in a 9.5\% increase in fuel economy. The Jaguar used 4.1 gallons with the system off, and 3.6 gallons with the system on, resulting in a 10.9\% increase in fuel economy. The Mini Cooper used in 2.7 gallons with the stop-start system off, and 2.6 gallons with the system on, resulting in a $2.9 \%$ increase, while the air conditioning was on. With the air conditioning off, and the stop-start system off, the Mini Cooper used 2.7 gallons, and 2.4 gallons with the system on, leading to a $9.5 \%$ increase in fuel efficiency [2].

Though this test was limited in size with only a test against the control, this illustrates a point that, through a range of engine sizes and types of cars, a start-stop system can greatly improve the fuel economy of cars especially in a high traffic city environment. Increasing improvements to the design and materials of the starter also improve the reliability of the starter now being able to perform many thousand more duty cycles than have previously been accomplished by earlier generations of starters. Regarding the savings that a well-designed startstop system the Department of Natural Resources of Canada claims, "Over 10 years, a vehicle with an idle stop-start system can save you $\$ 260$ to $\$ 1,540$ and reduce your carbon dioxide $\left(\mathrm{CO}_{2}\right)$ emissions by 610 to $3,540 \mathrm{~kg}[3] . "$

Another technology used and increasingly common in vehicles coming from manufactures is the turbocharger. A turbocharger forces air that is collected from the exhaust to recycle back into the engine to enter at a higher pressure, allowing more air to enter a cylinder. Due to the increase of air and fuel to retain the proper proportions, the combustion ignites with more force, with the ability of moving the pistons more efficiently. With this higher pressure, smaller turbocharged engines can produce similar power as a larger naturally aspirated engine.

\section{Projects from Industry}

In 2010, The Department of Energy launched a project called the 'SuperTruck Program' focused on making the Class 8 tractor trucks more fuel-efficient. As of 2016 commercial trucks hauls as much as $80 \%$ of the goods in the country and consume about $20 \%$ of the fuel, although they make up only $4 \%$ of vehicles on the road [5]. The program had three main objectives; first, to develop and demonstrate 50\% freight efficiency improvement from a 2009 model year Class 8 tractor truck, which translates to reaching almost 10 miles per gallon. Second, improve engine efficiency by $8 \%$, to achieve $50 \%$ brake thermal efficiency in a demonstration truck, and thereby 
boost fuel efficiency by $16 \%$. Finally, show pathways for a further $5 \%$ improvement in engine efficiency [6]." Four teams were involved in the program, Cummins-Peterbilt, Daimler-Detroit Diesel, Volvo, and Navistar.

The Cummins-Peterbilt team used a unique approach to aerodynamics than the other teams, creating a tractor truck set for increased aerodynamics, however some aerodynamic advantage was lost if they used a standard trailer with the setup. The trailer also incorporated retractable trailer skirts for better access to the wheels. The powertrain consisted of a $15 \mathrm{~L}$ ISX engine with a very high compression ratio and a high efficiency turbo. The result was a 40\% reduction in fuel consumption and freight efficiency increased to 178 ton-mile/gal [7].

The Daimler-Detroit Diesel team's powertrain included a Detroit Diesel DD15 10.7 L engine with a hybrid powertrain managing the starter, hotel loads, and idle management. Solar panels installed onto the cab roof charge a hybrid battery, resulting in a $47.4 \%$ reduction in fuel consumption [7].

The Navistar team was later to finish the project due to a temporary delay in 2012, resumed in 2014, and finished in 2016. The most notable aerodynamic aspect is the active pitch control system. At speeds above $50 \mathrm{mph}$, the front and rear suspension drops by 1.5 to 2 inches and an airfoil-like shape forms. An N13 engine with a GPS cruise control powers the truck to improve efficiency. As a result, the team obtained a $104 \%$ improvement in freight efficiency and $50.5 \%$ increase in brake thermal efficiency [7].

The Volvo team used an $11 \mathrm{~L}$ engine with a redesigned engine architecture. They found that if the piston bowl was redesigned the piston bowl to have protrusions coming out of the walls more oxygen would be available for the combustion process, which allowed for a $90 \%$ reduction in soot amount. The results from the project were a 56\% increase in brake thermal efficiency and an $88 \%$ improvement of freight efficiency [8]. 


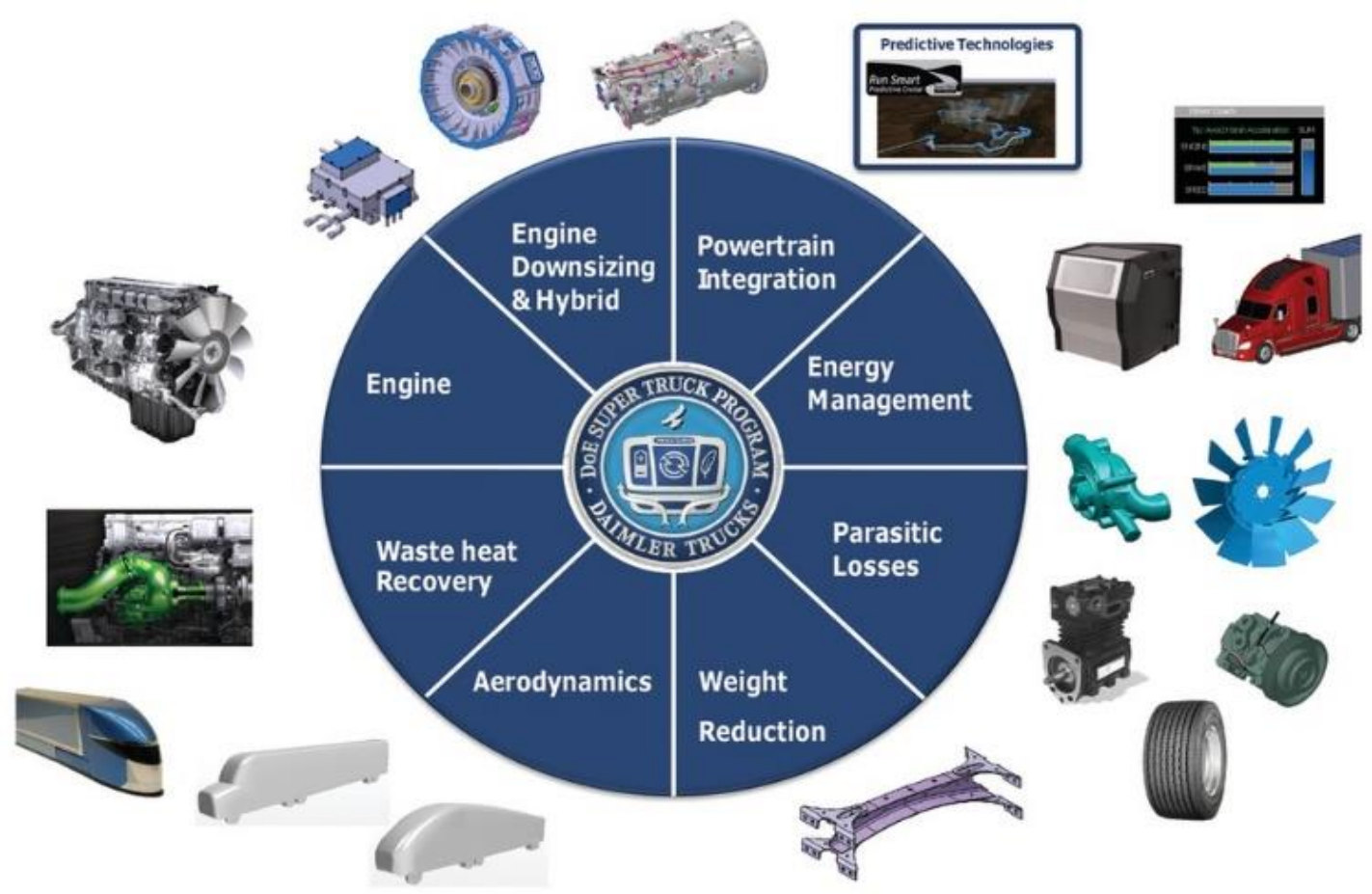

[9]

The project resulted in the commercial transportation sector benefitting immensely with many innovations that improves fuel efficiency. In addition, the automotive industry has benefited as well, because of the many technologies that can trickle down into passenger vehicles. As we create new technology and improved becoming more economical, production increases at the consumer level. The project has increased the understanding of aerodynamics and the effects materials have on the performance of the truck; also, the participating companies have enhanced their methods of simulating the testing of fuel efficiency, and overall capability of their vehicles.

Technologies cleaning up the atmosphere

Carbon capture is a newer technology still in development that may aid in removing some carbon dioxide from the atmosphere. Carbon capture, also known as direct air capture, is a technology in which a series of collector's processes air from the atmosphere, and through a series of chemical transformations removes $\mathrm{CO}_{2}$, then purifying and pressurizes the gas to transport it. There are several companies now that have varying processes to filter the $\mathrm{CO}_{2}$ out of the atmosphere, however it is still an emerging technology that is yet to be proven at a large 
scale, but the many test sites that are operational, they are showing promise. A company called Carbon Engineering is one of the leading companies in the field and has an operational plant in Canada, does claim that scaling up is not only possible, but can make a real impact on the amount of $\mathrm{CO}_{2}$ in the atmosphere.

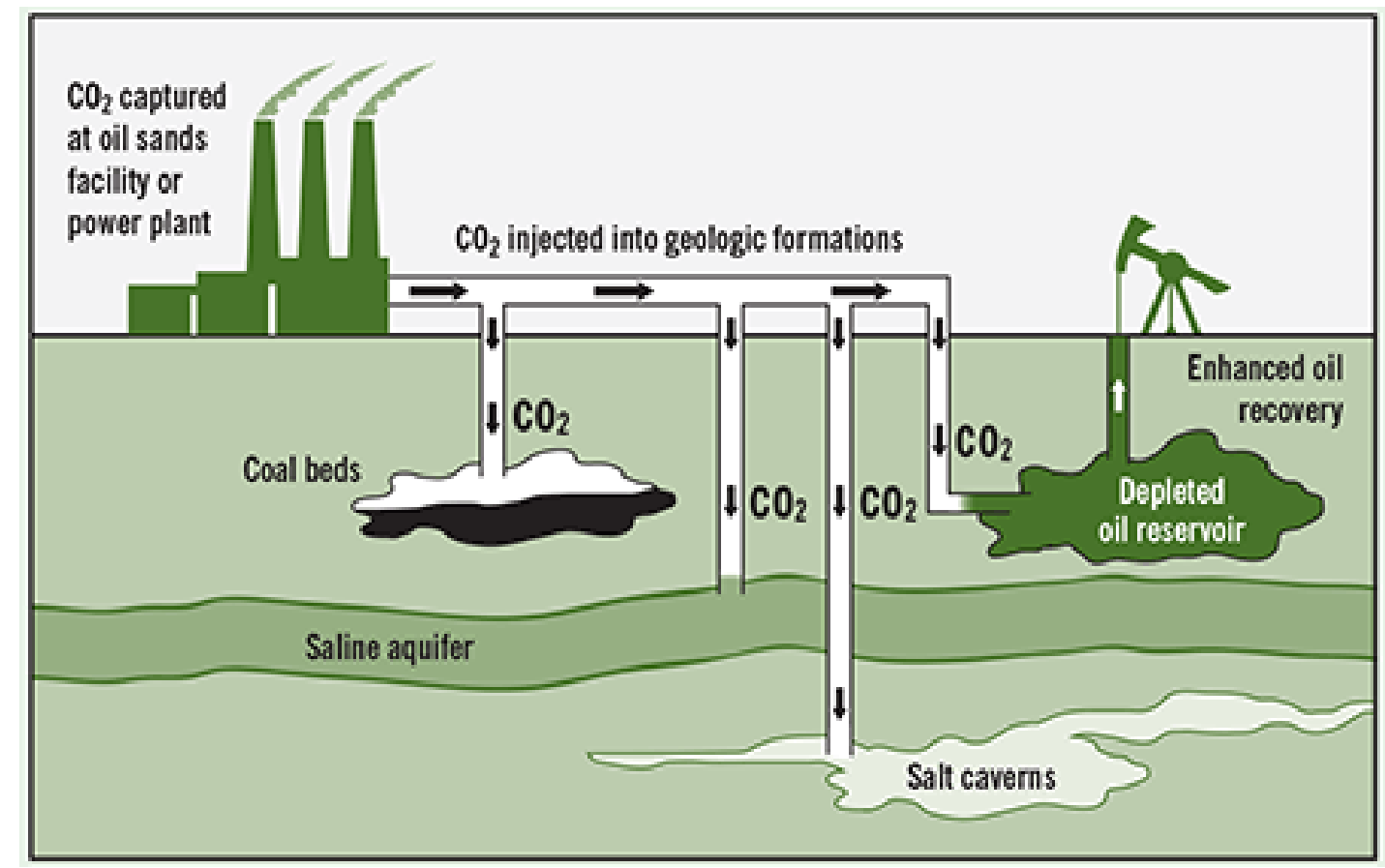

$[10]$

Once the carbon dioxide is captured, it is placed into long-term storage or used industry. Storing carbon dioxide typically includes pumping it deep in porous geological formations, such as former gas and oil fields or deep saline formations. Over time, the carbon dioxide will react with the porous rocks, or the salty water reducing the mobility and ability to escape to the surface. This method of storing carbon dioxide has been in practice for more than 30 years and there is a positive outlook on the effectiveness of this strategy. Another approach instead of simply storing carbon dioxide a few companies are focusing on recycling the captured carbon dioxide in the manufacturing of materials, this includes creating plastics or making gasoline with ultra-low carbon intensity. If a company can recycle this carbon dioxide, they may create a 'neutral-emission' product. As of 2018, a few companies that have test sites are in the process of refining the technology to be economical at the appropriate scale. 


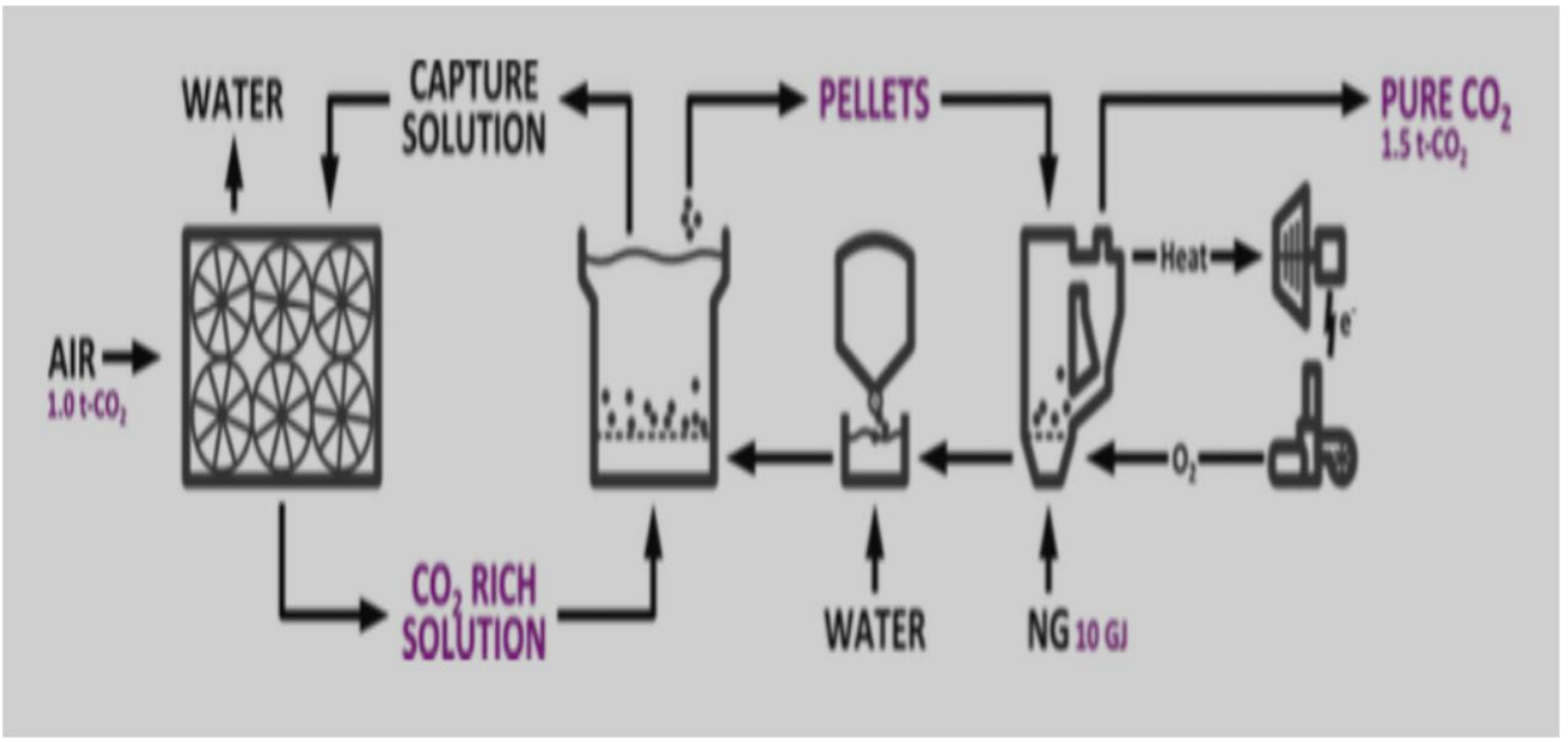

[11]

For the co-op program's duration, I worked with a professor who mentored me, gave advice in the automotive industry, that has evolved over many years. Over the past several years that I attended the university, I changed my major several times, in and out of fields of engineering, business, and physiology, stemming from the lack of information available during the process of choosing a major. While in the program I was able to meet with several engineers working in the industry and discuss functions each of them held within their companies, and how they prepared academically to succeed in their respective industry. During the time of the project and participating in several academic societies including the American Society of Engineering Education and the American Chemical Society, I decided to pursue a duel major in mechanical engineering and material science engineering emphasizing on renewable energy. The knowledge that I gained from this program were invaluable for many aspects of my life, and would be the same for many other students who are struggling to find a major that suits their interests and goals in life, whether it be in engineering or another STEM field. As a result of this I am in contact with a department chair at my university to find a way to implement a program similar to this one that is more accessible to students arriving at the school to help them decide early on. I am also contacting various local high schools to find interest in a type of program that would allow students to research their interests while also learning how academic research is conducted. 


\section{References}

[1] K. Leu, "Beginning College Students Who Change Their Majors Within 3 Years of Enrollment," nces.ed.gov, Dec. 7, 2107. [Online]. Available: https://nces.ed.gov/pubsearch/pubsinfo.asp?pubid=2018434. [Accessed: 03-Jan-2018].

[2] D. Edmunds, "Do Stop-Start Systems Really Save Fuel?," Edmunds.com, 30-Nov-2014. [Online]. Available: https://www.edmunds.com/car-reviews/features/do-stop-startsystems-really-save-fuel.html. [Accessed: 03-Jan-2019].

[3] “Idle stop-start technology," Natural Resources Canada, 04-Sep-2018. [Online]. Available: https://www.nrcan.gc.ca/energy/efficiency/transportation/21020. [Accessed: 05-Dec-2018].

[4] V. Shah, "Tech Through Time: How Turbocharging Works," CarsGuide, 23-Aug-2018. [Online]. Available: https://www.carsguide.com.au/oversteer/tech-through-timeturbocharging-59162. [Accessed: 21-Dec-2018].

[5] P. Lester and C. Wilkins, "INFOGRAPHIC: How SuperTruck is Making Heavy Duty Vehicles More Efficient," Department of Energy, 01-Mar-2016. [Online]. Available: https://www.energy.gov/articles/infographic-how-supertruck-making-heavy-dutyvehicles-more-efficient. [Accessed: 25-Jan-2019].

[6] O. Delgado and N. Lutsey, The U.S. SuperTruck Program: Expediting the Development of Advanced Heavy-Duty Vehicle Efficiency Technologies. Washington DC: International Council on Clean Transportation, 2014, p. 2.

[7] J. Park, "How Navistar's SuperTruck Exceeded Goals," Fleet Management - Trucking Info, 20-Dec-2016. [Online]. Available: https://www.truckinginfo.com/157131/hownavistars-supertruck-exceeded-goals. [Accessed: 20-Dec-2018].

[8] "SuperTruck Powertrain Technologies for Efficiency Improvement." United States Department of Energy, 10-Jun-2016.

[9] S. Jensen, "It's a bird...it's a plane...its SuperTruck," OEM Off-Highway, 01-Feb-2012. [Online]. Available: https://www.oemoffhighway.com/trends/hybrids/article/10602353/ doe-supertruck-program-updates. [Accessed: 21-Jan-2019].

[10] “Carbon Capture - Utilization \& Storage,” EnergyWatch, 10-Jul-2018. [Online]. Available: https://energywatch-inc.com/carbon-capture-utilization-storage-pipe-dreampotential-solution/. [Accessed: 02-Feb-2019].

[11] “About Direct Air Capture Technology,” Carbon Engineering. [Online]. Available: https://carbonengineering.com/about-dac/. [Accessed: 03-Feb-2019]. 